\title{
Evaluation of bacteriocin-producing lactic acid bacteria strains isolated from "nem chua Thu Duc"
}

Chi N. Vo, Phuong T. Nguyen*, Tuyet T. A. Nguyen, Khoa A. Dinh, Tuyen B. Phan, Hang D. Hoang, Thuy T. Le, \& Tuyen C. Kha

Faculty of Chemical Engineering and Food Technology, Nong Lam University, Ho Chi Minh City, Vietnam

\author{
ARTICLE INFO \\ Research Paper \\ Received: January 27, 2021 \\ Revised: April 10, 2021 \\ Accepted: April 16, 2021
}

\section{Keywords}

\section{Bacteriocin}

lactic acid bacteria (LAB)

Nem chua Thu Duc

Pediococcus pentosaceus

Weissella paramesenteroides

\section{${ }^{*}$ Corresponding author}

Nguyen Thi Phuong

Email: nguyenthiphuong@hcmuaf.edu.vn

\begin{abstract}
This study aimed to select some lactic acid bacteria (LAB) strains to produce bacteriocin isolated from two different local brand names of nem chua Thu Duc, a Vietnamese traditional fermented meat product. Eight different LAB strains were isolated from products. However, only Pediococcus pentosaceus isolated from 72-h fermented "Ba Chin" products and Weissella paramesenteroides isolated from 120$\mathrm{h}$ fermented "Diem" products were selectively screened for their bacteriocin production. The antimicrobial activity was detected by the agar diffusion method against Escherichia coli ATCC 25922, Salmonella enterica serovar Typhimurium ATCC 13076, Staphylococcus aureus ATCC 6538, and Bacillus cereus ATCC 25924 used as target strains. Bacteriocin of Pediococcus pentosaceus strain showed a high antibacterial ability with a sterile ring diameter that produces an average of 12.20 - $16.07 \mathrm{~mm}$. Bacteriocin of Weissella paramesenteroides strain only showed inhibitory activity on the growth of indicator microorganisms with an average inhibitory ring diameter of 9.75 - $15.27 \mathrm{~mm}$. In conclusion, it seems like both bacteriocin-producing $P$. pentosaceus and W. paramesenteroides give potential applications as a starter culture, bio-preservation and bio-safety control in fermented meat as well as other kinds of fermented foods.
\end{abstract}

Cited as: Vo, C. N., Nguyen, P. T., Nguyen, T. T. A., Dinh, K. A., Phan, T. B., Hoang, H. D., Le, T. T., \& Kha, T. C. (2021). Evaluation of bacteriocin-producing lactic acid bacteria strains isolated from "nem chua Thu Duc". The Journal of Agriculture and Development 20(2), 62-68. 


\title{
Khảo sát khả năng sinh bacteriocin của vi khuẩn lactic phân lập trên nem chua Thủ Đức
}

\author{
Võ Ngọc Chi, Nguyễn Thị Phượng*, Nguyễn Thị Ánh Tuyết, Đinh Anh Khoa, \\ Phan Bích Tuyền, Hoàng Diễm Hằng, Lê Thị Thủy \& Kha Chấn Tuyền
}

Khoa Công Nghệ Hóa Học và Thực Phẩm, Trường Đại Học Nông Lâm TP.HCM, TP. Hồ Chí Minh

\section{THÔNG TIN BÀI BÁO}

Bài báo khoa học

Ngày nhận: 27/01/2021

Ngày chỉnh sửa: 10/04/2021

Ngày chấp nhận: 16/04/2021

\section{Từ khóa}

Bacteriocin

Nem chua Thủ Đức

Pediococcus pentosaceus

Vi khuẩn lactic

Weissella paramesenteroides

* Tác giả liên hệ

Nguyễn Thị Phượng

Email: nguyenthiphuong@hcmuaf.edu.vn

\section{TÓM TẮT}

Mục đích của nghiên cứu là tuyển chọn được các chủng vi khuẩn lactic có khả năng sinh bacteriocin được phân lập trên nem chua tại Thủ Đức. Kết quả cho thấy có 2 trong số 8 chủng vi khuẩn lactic được phân lập, có khả năng sinh bacteriocin là Pediococcus pentosaceus trên nem chua Bà Chín lên men ngày thứ 3 và Weissella paramesenteroides trên nem chua Diễm lên men ngày thứ 5 . Hoạt tính kháng khuẩn của chủng Pediococcus pentosaceus và chủng Weissella paramesenteroides được phát hiện bằng phương pháp khuếch tán thạch đều cho thấy hoạt tính đối kháng với cả 4 chủng vi sinh vật chỉ thị là Escherichia coli ATCC 25922, Salmonella enterica serova Typhimurium ATCC 13076, Staphylococcus aureus ATCC 6538 và Bacillus cereus ATCC 25924. Bacteriocin của chủng Pediococcus pentosaceus có khả năng kháng khuẩn tốt với đường kính vòng vô khuẩn tạo ra trung bình từ $12,20-16,07 \mathrm{~mm}$. Đối với bacteriocin của chủng Weissella paramesenteroides chỉ cho thấy hoạt tính ức chế sự phát triển của các chủng vi sinh vật chỉ thị với đường kính vòng ức chế trung bình từ 9,75-15,27 mm. Tóm lại có thể ứng dụng 2 chủng vi khuẩn lactic này trong việc tạo ra các chế phẩm bacteriocin sinh học thay thế các chất bảo quản hóa học kéo dài thời gian sử dụng sản phẩm thực phẩm.

\section{1. Đặt Vấn Đề}

Nem chua là một sản phẩm thịt lên men truyền thống rất được ưa chuộng tại Việt Nam, đây là một ứng dụng điển hình của lên men acid lactic trong thực phẩm. Vi khuẩn lactic là tác nhân quan trọng để lên men thịt, chúng có thể ức chế sự phát triển của vi sinh vật khác bao gồm vi khuẩn gây độc và hư hỏng thực phẩm vì chúng sản sinh ra nhiều loại chất kháng khuẩn chẳng hạn như các acid hữu cơ, hydro peroxide, diacetyl và bacteriocin (Pilasombut \& ctv., 2015). Bacteriocin của vi khuẩn lactic được nghiên cứu nhiều nhất do tính ưu việt của chúng trong bảo quản thực phẩm cũng như tính an toàn với người sử dụng (Woraprayote \& ctv., 2016). Bacteriocins thường không làm gây ra những thay đổi trong sản phẩm thực phẩm và có thể được sử dụng như một phụ gia bổ sung trong chế biến thực phẩm, giảm cường độ của các phương pháp xử lý truyền thống, chẳng hạn như gia nhiệt. Hiện nay, xu hướng về tiêu dùng các loại sản phẩm thực phẩm với hương vị tươi ngon và không sử dụng hóa chất bảo quản ngày càng tăng cao. Vì vậy, các chất bảo quản có nguồn gốc tự nhiên và có hoạt tính kháng khuẩn sinh học như LAB bacteriocin được tìm kiếm để ứng dụng vào ngành công nghiệp thực phẩm thay thế các chất bảo quản hóa học bảo vệ sức khỏe người tiêu dùng thực phẩm.

\section{Vật Liệu và Phương Pháp Nghiên Cứu}

\subsection{Vật liệu}

Nem Bà Chín được thu thập từ cơ sở nem Bà Chín ở địa chỉ: số 58 đường Trần Hưng Đạo, 
Phường Hiệp Phú, Quận 9, Thành phố Hồ Chí Minh và Nem Diễm được thu thập từ cơ sở nem Diễm ở địa chỉ: số 41 đường Lê Văn Ninh, Phường Linh Tây, Quận Thủ Đức, Thành phố Hồ Chí Minh.

Chủng vi sinh vật chỉ thị bao gồm: Escherichia coli ATCC 25922, Salmonella enterica serova Typhimurium ATCC 13076, Staphylococcus aureus ATCC 6538, Bacillus cereus ATCC 25924. Bốn chủng vi sinh vật chỉ thị được cung cấp bởi Viện Công nghệ Thực phẩm, Trường Đại học Công Nghiệp TP.HCM.

Môi trường: MRS broth, MRS agar, TSB, TSA (Himedia, Ấn Độ).

Hóa chất: $\mathrm{NaCl} 0,85 \%$, glycerol, $\mathrm{H}_{2} \mathrm{O}_{2} 3 \%$, cồn $95 \%, \mathrm{CaCO}_{3}, \mathrm{NaOH}$, Crystal Violet, Safranin, Lugol.

Thuốc thử: Đĩa giấy thử phản ứng oxydase.

\subsection{Phương pháp nghiên cứu}

Phân lập vi khuẩn: $225 \mathrm{~mL}$ dung dịch $\mathrm{NaCl}$ $0,85 \%$ vô trùng được cho vào bao $\mathrm{PE}$ vô trùng có chứa $25 \mathrm{~g}$ nem chua. Sau đó, đặt túi mẫu vào trong máy dập mẫu và đồng nhất trong vòng 1 phút để tạo thành dung dịch huyền phù mẹ có nồng độ $10^{-1}$. Dịch huyền phù được xác định $\mathrm{pH}$, sau đó tiếp tục được pha loãng đến nồng độ $10^{-8}$ (Mathara \& ctv., 2004). Tiến hành cấy đĩa ở các nồng độ $10^{-5}, 10^{-6}, 10^{-7}$ và $10^{-8}$. Dùng micropipette hút $100 \mu \mathrm{L}$ dung dịch pha loãng cho lên bề mặt đĩa thạch MRS. Dùng que cấy trang đã tiệt trùng dàn đều dịch cho đến khi bề mặt thạch khô. Đĩa thạch được đem đi ủ kỵ khí trong 48 giờ ở $37^{\circ} \mathrm{C}$.

Tuyển chọn các chủng vi khuẩn lactic bằng cách tiến hành xác định hình thái khuẩn lạc, nhuộm Gram, xác định đặc điểm tế bào, đồng thời khảo sát khả năng di động và kiểm tra các phản ứng sinh hóa như catalase, oxydase, khả năng sinh acid lactic của các chủng vi khuẩn đã phân lập được.

Gia tăng sinh khối và thu dịch ly tâm sinh khối: Dùng que cấy tiệt trùng lấy 1 vòng que cấy vi khuẩn trong ống gốc eppendorf cho vào ống ly tâm vô trùng có chứa $10 \mathrm{~mL}$ MRS. Các ống ly tâm này được ủ ở $37^{\circ} \mathrm{C}$ trong 16 - 18 giờ (Hoa \& ctv., 2012). Các ống ly tâm sẽ được đem ly tâm ở 8000 vòng trong 15 phút ở $4^{\circ} \mathrm{C}$ thu dịch nổi. Nhằm tránh ảnh hưởng đến kết quả thí nghiệm bởi sự ức chế gây ra bởi các acid hữu cơ có mặt trong môi trường, sau khi ly tâm xong dịch nổi được điều chỉnh $\mathrm{pH}$ bằng $\mathrm{NaOH} 1 \mathrm{~N}$ để đạt $\mathrm{pH}$ 6,8 - 7,0 (Nguyen \& ctv., 2017). Sau đó lấy phần dịch nổi bơm qua màng lọc Minisart $(\mathrm{d}=0,2 \mu \mathrm{M})$ để tách cặn khuẩn còn sót lại. Phần dịch lỏng thu được sẽ được sử dụng cho các thí nghiệm tiếp theo.

Khảo sát khả năng sinh bacteriocin bằng phương pháp khuếch tán đĩa giấy theo Kirby Bauer. Tiến hành tăng sinh 4 chủng vi sinh vật chỉ thị bao gồm Escherichia coli, Salmonella Typhimurium, Bacillus cereus và Staphylococcus aureus trong ống nghiệm chứa $10 \mathrm{~mL}$ môi trường TSB nuôi ở $30^{\circ} \mathrm{C}$ trong $8-10$ giờ. Sau đó $100 \mu \mathrm{L}$ mỗi dung dịch được trải trên đĩa thạch TSA. Đặt đĩa giấy đã được vô trùng có kích thước $\mathrm{d}=7 \mathrm{~mm}$ (4 - 6 đĩa giấy) trên đĩa môi trường thạch, dùng micropipette hút $20 \mu \mathrm{L}$ dịch ly tâm của LAB ở trên cho vào từng đĩa giấy. Các đĩa được giữ trong tủ lạnh ở $4^{\circ} \mathrm{C}$ trong 4 giờ và sau đó ủ ở $30^{\circ} \mathrm{C}$ trong 24 giờ.

Định danh các dòng vi khuẩn lactic có khả năng sinh bacteriocin với phương pháp thực hiện như sau: Tách chiết DNA và thực hiện $\mathrm{PCR}$ với mồi đặc hiệu vùng $16 \mathrm{~s}$. Sau đó giải trình tự trực tiếp rồi so sánh trình tự với ngân hàng dữ liệu NCBI bằng công cụ BLAST SEARCH từ đó xác định mẫu vi khuẩn thuộc loài nào.

\subsection{Phương pháp xử lí số liệu thống kê}

Số liệu được xử lí bằng phần mềm Microsoft Excel 2013 và Statgraphics với độ tin cậy là $95 \%$.

\section{Kết Quả và Thảo Luận}

\subsection{Hoạt tính kháng khuẩn của bacteriocin từ các dòng vi khuẩn lactic phân lập được}

Nguyen \& ctv., (2013) đã phân lập được các chủng LAB từ nem chua bao gồm: Lactobacillus pentosus, Lb. plantarum, Lb. brevis, Lb. paracasei, Lb. fermentum, Lb. acidipiscis, Lb. farciminis, Lb. rossiae, Lb. fuchuensis, Lb. namurensis, Lc. lactis, Leuconostoc citreum, Leuconostoc fallax, Pediococcus acidipiscis, Pediococcus pentosaceus, Pediococcus stilesii, Weissella cibaria và Weissella paramesenteroides. LAB là tác nhân quan trọng để lên men thịt, chúng có thể ức chế sự phát triển của vi sinh vật khác bao gồm vi khuẩn gây độc và hư hỏng thực phẩm vì chúng sản sinh ra nhiều loại chất kháng khuẩn chẳng 


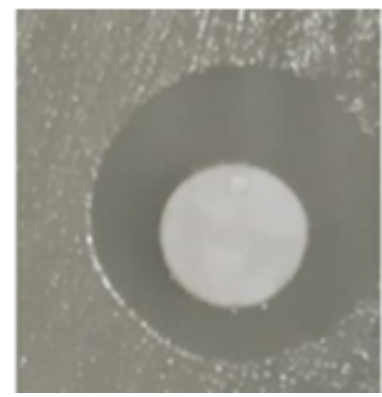

S. aureus

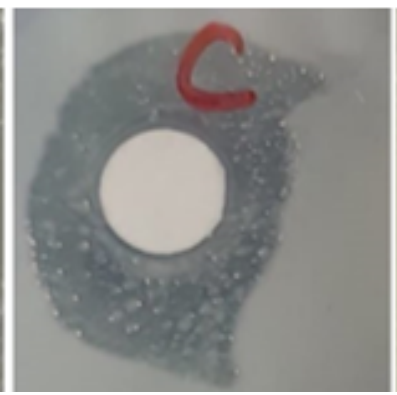

B. cereus

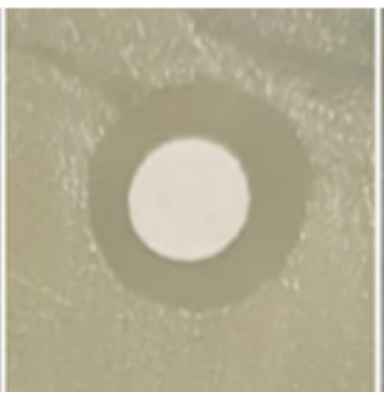

S. Typhimurium

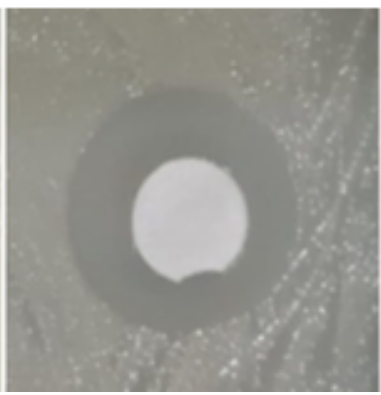

E. coli

Hình 1. Hoạt tính kháng khuẩn của chủng vi khuẩn lactic LAB1.

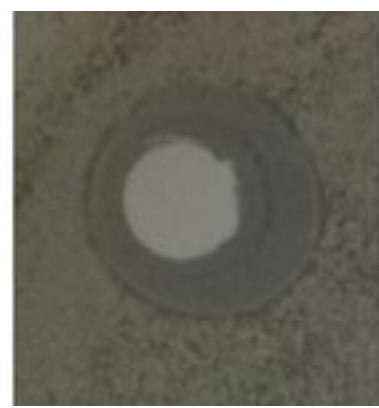

S. aureus

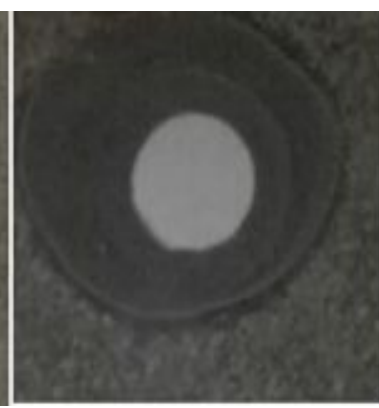

B. cereus

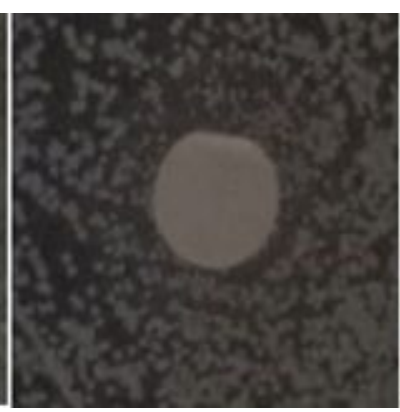

E. coli

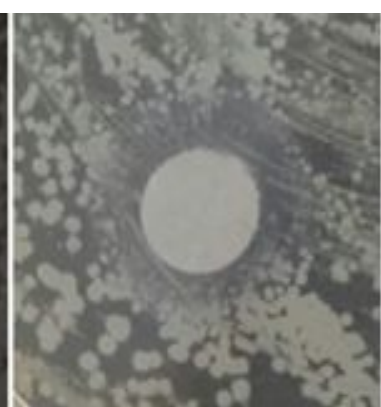

S. Typhimurium

Hình 2. Hoạt tính ức chế của chủng vi khuẩn lactic LAB2 trên môi trường TSA.

Bảng 1. Đường kính vòng kháng khuẩn của LAB1 trên môi trường TSA

\begin{tabular}{ccccc}
\hline \multirow{2}{*}{$\begin{array}{l}\text { Vi } \\
\text { khuẩn }\end{array}$} & \multicolumn{4}{c}{ Đường kính vòng kháng khuẩn của chủng vi khuẩn lactic LAB1 $\left(\mathrm{d}_{\mathrm{kk}}\right) \mathrm{mm}$} \\
\cline { 2 - 5 } $\begin{array}{c}\text { Đường } \\
\text { kính }\end{array}$ & $13,53^{\mathrm{a}} \pm 0,21$ & $16,07^{\mathrm{b}} \pm 0,21$ & $12,80^{\mathrm{ac}} \pm 0,20$ & $12,20^{\mathrm{c}} \pm 0,70$ \\
\hline
\end{tabular}

a,b,c Các ký tự khác nhau thể hiện sự khác biệt có ý nghĩa về mặt thống kê với độ tin cậy $95 \%$.

Bảng 2. Đường kính vòng ức chế LAB2 trên môi trường TSA

\begin{tabular}{ccccc}
\hline \multirow{2}{*}{$\begin{array}{l}\text { Vi } \\
\text { khuẩn }\end{array}$} & \multicolumn{4}{c}{ Dường kính vòng kháng khuẩn của chủng vi khuẩn LAB2 $\left(\mathrm{d}_{\mathrm{kk}}\right) \mathrm{mm}$} \\
\cline { 2 - 5 } $\begin{array}{c}\text { Đường } \\
\text { kính }\end{array}$ & $11,90^{\mathrm{a}} \pm 0,36$ & $15,27^{\mathrm{b}} \pm 0,35$ & $9,75^{\mathrm{c}} \pm 0,36$ & $11,78 \mathrm{a} \pm 0,27$ \\
\hline $\begin{array}{l}\text { a,b,c Các ký tự khác nhau thể hiện sự khác biệt có ý nghĩa về mặt thống kê với độ tin cậy } 95 \% .\end{array}$
\end{tabular}

hạn như các acid hữu cơ, hydro peroxide, diacetyl và bacteriocin (Pilasombut \& ctv., 2015).

Kết quả nghiên cứu trên 8 chủng vi khuẩn lactic phân lập được từ 2 loại nem chua Thủ Đức đối với 4 chủng vi sinh vật chỉ thị cho thấy có 2 chủng vi khuẩn lactic có khả năng sinh bacteriocin là chủng LAB1 (được phân lập từ nem Bà Chín) và LAB2 (được phân lập từ nem Diễm) (Hình 1 và 2). Chủng vi khuẩn LAB1 được phân lập từ nem Bà Chín kháng cả 4 chủng vi sinh vật gây bệnh chỉ thị và có đường kính vòng kháng khuẩn trung bình từ 12,20 - 16,07 mm (Bảng 1). Trong khi đó, chủng vi khuẩn LAB2 được phân lập từ nem Diễm có hoạt tính ức chế đối với 4 chủng vi sinh vật chỉ thị với đường kính vùng ức chế trung bình từ 9,75 - 15,27 mm (Bảng 2). Trong nghiên cứu này cả 2 chủng vi khuẩn LAB1và LAB2 đều cho thấy hoạt tính đối kháng với cả vi khuẩn Gram âm và vi khuẩn Gram dương. Nhìn chung đường kính vòng tròn kháng khuẩn hay ức chế của bacteriocin được sản sinh bởi vi khuẩn lactic đối với 

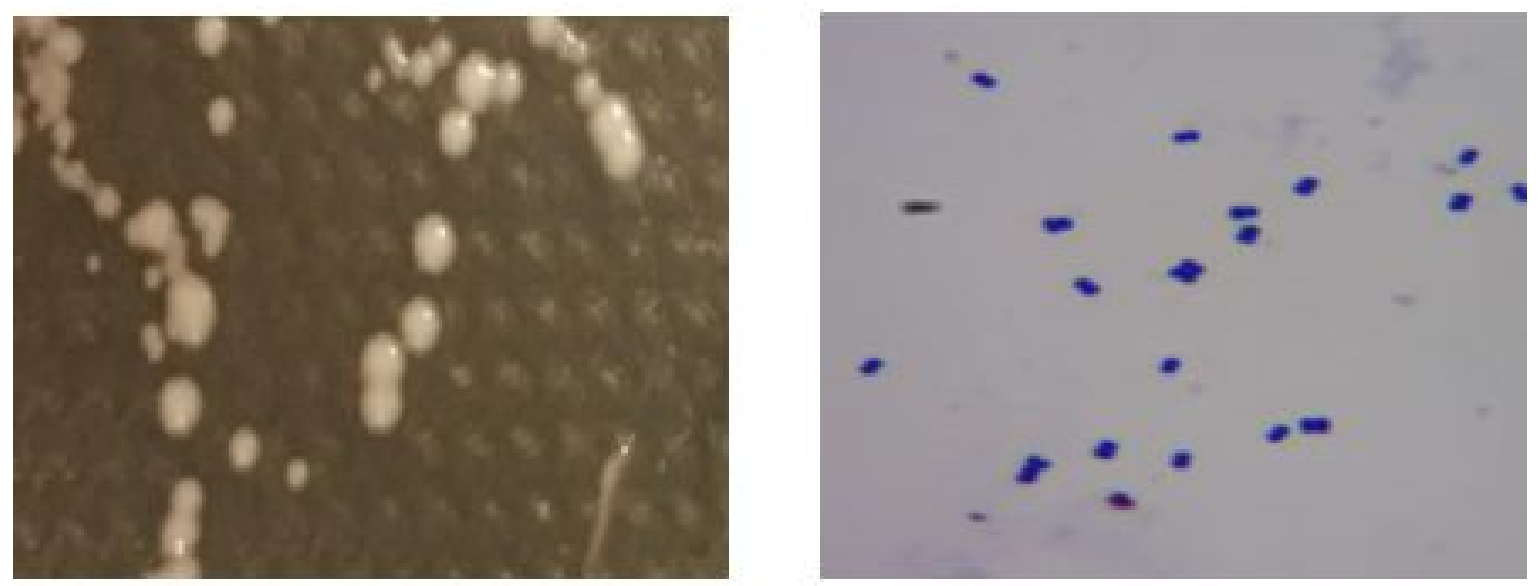

Hình 3. Dạng khuẩn lạc và đặc điểm tế bào của mẫu LAB1.

TRINH TƯ CHI TIET MĀU THƯ
>II9240-F
CCTGGCTCAGGATGAACGCTGGCGGCGTGCCTAATACATGCAAGTCGAACGAACTT
CCGTTAATTGATTATGACGTACTTGTACTGATTGAGATTTAACACGAAGTGAGTGG
CGAACGGGTGAGTAACACGTGGGTAACCTGCCCAGAAGTAGGGGATAACACCTGG
AAACAGATGCTAATACCGTATAACAGAGAAACCGCATGGTTTCTTITAAAGATG
GCTCTGCTATCACTTCTGGATGGACCCGCGGCGTATTAGCTAGTTGGTGAGGTAAA
GGCTCACCAAGGCAGTGATACGTAGCCGACCTGAGAGGGTAACGGCCACATTGG
GACTGAGACACGGCCCAGACTCCTACGGGAGGCAGCAGTAGGGAATCTTCCACAA
TGGACGCAAGTCTGATGGAGCAACGCCGCGTGAGTGAAGAAGGGTTTCGGCTCGT
AAAGCTCTGTTGTTAAAGAAGAACGTGGGTAAGAGTAACTGTTTACCCAGTGACGGT
ATTTAACCAGAAAGCCACGGCTAACTACGTGC

Hình 4. Trình tự gen chi tiết của mẫu LAB1.
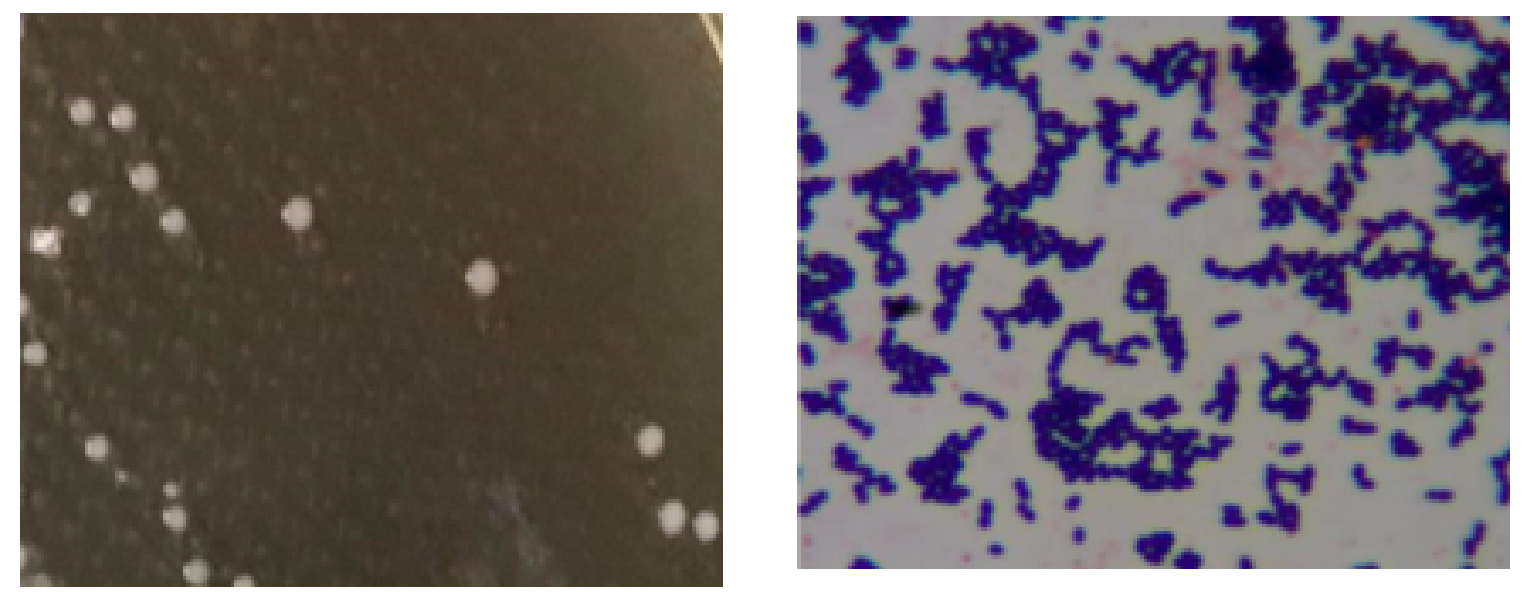

Hình 5. Dạng khuẩn lạc và đặc điểm tế bào của mẫu LAB2.

vi khuẩn Gram dương là lớn hơn so với vi khuẩn Gram âm. Vì vi khuẩn Gram dương chỉ có một lớp lipid, chúng thường nhạy cảm hơn so với vi khuẩn Gram âm. Sự khác biệt này là vì vi khuẩn Gram âm có màng ngoài và không gian chu chất trong khi ở vi khuẩn Gram dương thì không tìm 


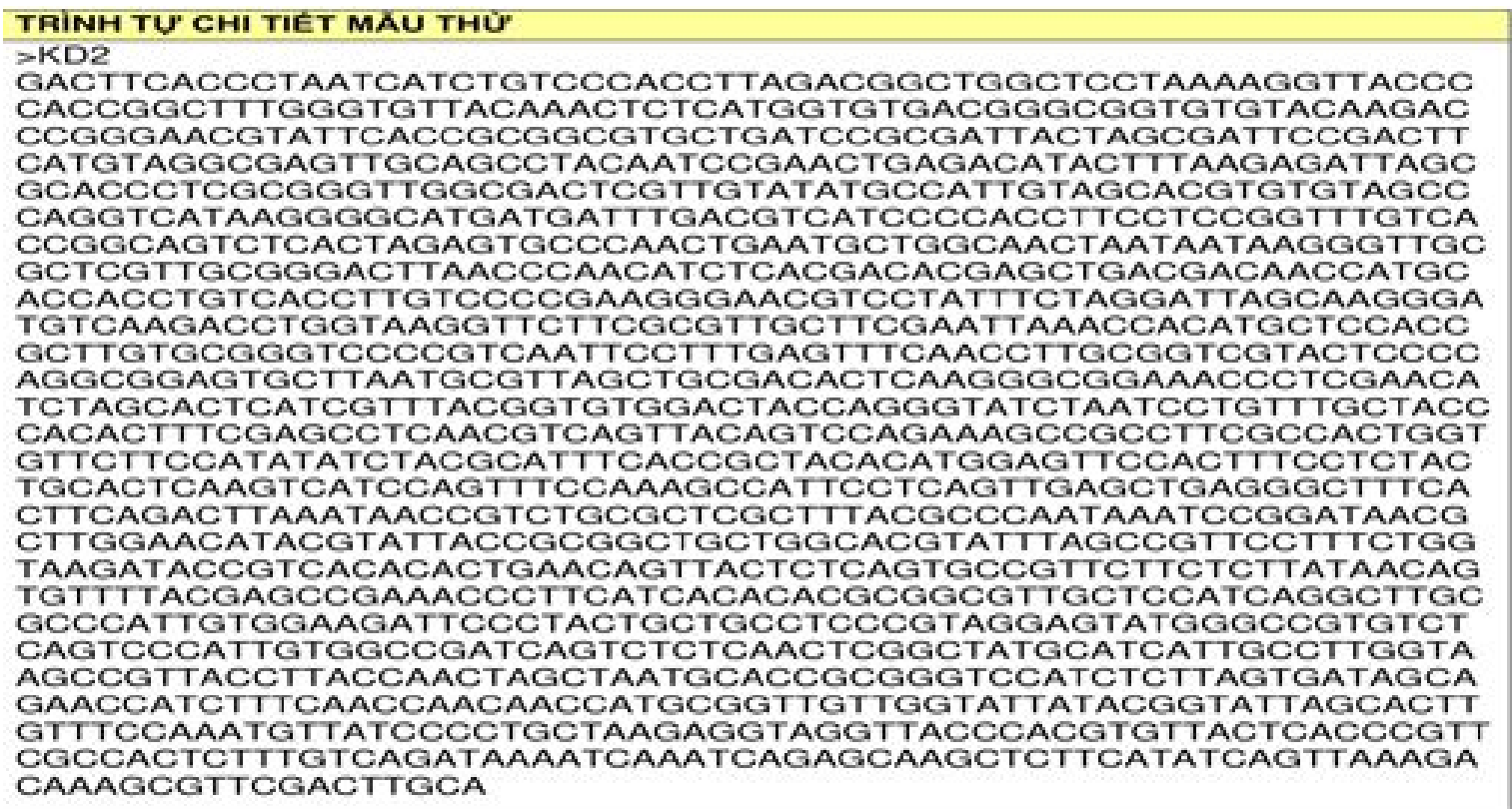

Hình 6. Trình tự gen chi tiết của mẫu LAB2.

thấy (Ceylan \& Fung, 2007).

3.2. Kết quả định danh các dòng vi khuẩn lactic sinh bacteriocin

Kết quả giải trình tự gen cho thấy mẫu LAB1 thuộc loài Pediococcus pentosaceus với mức tương đồng $100 \%$ (Hình 4). Với đặc điểm khuẩn lạc là khuẩn lạc tròn, bóng, vun cao, màu trắng sữa, rìa nguyên, đường kính khoảng 2 - 3 mm (Hình 3). Và đặc điểm tế bào như sau: Tế bào có dạng hình cầu đôi, cầu tứ, tế bào vi khuẩn Gram dương. Theo Bajpai \& ctv. (2016), dịch ly tâm sinh khối của Pediococcus pentosaceus thể hiện tác dụng kháng khuẩn đáng kể $(P<0,05)$ với đường kính của vùng ức chế $(16,5$ - 20,4 mm) chống lại các vi khuẩn gây bệnh trong thực phẩm.

Kết quả giải trình tự gen cho thấy mẫu LAB2 thuộc loài Weissella paramesenteroides với mức tương đồng $100 \%$ (Hình 6). Với đặc điểm khuẩn lạc là khuẩn lạc tròn, màu trắng sưa, rìa nguyên, vun nhẹ, đường kính từ 1 - 2 mm (Hình 5). Và đặc điểm tế bào như sau: Tế bào có dạng cầu trực, kết chuỗi, tế bào vi khuẩn Gram dương. Papagianni \& Papamichael (2011) đã chỉ ra rằng Weissella paramesenteroides tạo ra một bacteriocin có tên là weissellin $\mathrm{A}$, có khả năng chịu nhiệt lên đến $121^{\circ} \mathrm{C}$ trong 1 giờ, và duy trì hoạt động của nó trong phạm vi pH từ 2 - 10 hoạt động chống lại đa số các vi khuẩn Gram dương. Các đặc tính của weissellin $\mathrm{A}$ làm cho nó trở thành một tác nhân đầy hứa hẹn trong việc bảo quản thực phẩm.

\section{Kết Luận}

Trong nghiên cứu này, 8 chủng vi khuẩn lactic trên hai loại nem chua tại Thủ Đức là nem Bà Chín và nem Diễm đã được phân lập. Từ kết quả khảo sát khả năng kháng khuẩn của 8 chủng vi khuẩn lactic này trên 4 chủng vi sinh vật chỉ thị bao gồm Escherichia coli, Salmonella Typhimurium, Bacillus cereus và Staphylococcus aureus cho thấy có 2 chủng LAB có khả năng sinh bacteriocin đó là Pediococcus pentosaceus và Weissella paramesenteroides. Với khả năng sinh bacteriocin, 2 chủng này có thể đem lại nhiều tiềm năng mang tính ứng dụng trong việc tạo ra chất bảo quản thực phẩm tự nhiên.

\section{Lời Cảm Ơn}

Xin chân thành cảm ơn Trường Đại học Nông Lâm TP.HCM đã tài trợ cho chúng tôi thực hiện đề tài này (Mã số đề tài: CS-SV19-CNTP-04).

\section{Tài Liệu Tham Khảo (References)}

Bajpai, V. K., Han, J. H., Rather, I. A., Majumder, R., Nam, G. J., ChanSeo, P., Lim, J., Paek, W. K., \& Park, 
Y. H. (2016). Characterization of lactic acid bacterium Pediococcus pentosaceus 4I1 from freshwater fish Zacco koreanus and its antibacterial mode of action. PeerJ PrePrints 4, e2121v1.

Ceylan, D. C., \& Fung, Y. C., 2007. Antimicrobial activity of spices 1. Journal of Rapid Methods and Automation in Microbiology 12(1), 1-55.

Hoa, T. T. M., \& Nguyen, A. L. (2012). Classify of bacteria lactococcus PD14 synthesized bacteriocin. Vietnam Journal of Science and Technology 50(5), 635.

Mathara, J. M., Schillinger, U., Kutima, P. M., Mbugua, S. K., \& Holzapfel, W. H. (2004). Isolation, identification and characterisation of the dominant microorganisms of kule naoto: the Maasai traditional fermented milk in Kenya. International Journal of Food Microbiology 94(3), 269-278.

Nguyen, D. T. L., Hoang, V. T., Nguyen, T. T. T., \& Nguyen, A. H. (2016). Isolation and selection of lactic acid bacteria from Vietnamese fermented pork meat product with antimicrobial activity and characterization of bacteriocin. Vietnam Journal of Agricultural Science 14(7), 1089-1099.
Nguyen, D. T. L., Van Hoorde, K., Cnockaert, M., De Brandt, E., Aerts, M., \& Vandamme, P. (2013). A description of the lactic acid bacteria microbiota associated with the production of traditional fermented vegetables in Vietnam. International Journal of Food Microbiology 163(1), 19-27.

Papagianni, M., \& Papamichael, E. M. (2011). Purification, amino acid sequence and characterization of the class IIa bacteriocin weissellin A, produced by Weissella paramesenteroides DX. Bioresource Technology 102(12), 6730-6734.

Pilasombut, K., Rumjuankiat, K., Ngamyeesoon, N., \& Le, D. N. D. (2015). In vitro characterization of bacteriocin produced by lactic acid bacteria isolated from Nem Chua, a traditional Vietnamese Fermented Pork. Korean Journal for Food Science of Animal Resources 35(4), 473-478.

Woraprayote, W., Malila, Y., Sorapukdee, S., Swetwiwathana, A., Benjakul, S., \& Visessanguan, W. (2016). Bacteriocins from lactic acid bacteria and their applications in meat and meat products. Meat Science 120, 118-132. 